\title{
CARACTERÍSTICAS MORFOGÊNICAS E PERFILHAMENTO DO Panicum maximum Jacq. cv. TANZÂNIA IRRIGADO
}

\author{
Morphogenetic characteristics and tillering of irrigated Panicum maximum Jacq. cv. Tanzania
}

\author{
Fernando França da Cunha ${ }^{1}$, Antônio Alves Soares², Odilon Gomes Pereira ${ }^{3}$, \\ Daniel Moreira Lambertucci ${ }^{4}$, Franklin Vitor de Souza Abreu ${ }^{4}$
}

\begin{abstract}
RESUMO
Avaliou-se o efeito de diferentes turnos de rega e níveis de irrigação sobre as características morfogênicas e o perfilhamento de Panicum maximum Jacq. cv. Tanzânia. Uma bancada experimental foi montada sob ambiente protegido, onde foram colocados recipientes cultivados com o capim. As irrigações foram realizadas com turnos de rega de 1,4 e 7 dias, e lâminas de irrigação para restabelecer 50, 75 e $100 \%$ da disponibilidade total de água no solo. A densidade populacional de perfilhos foi obtida por meio de contagem de perfilhos vivos após cada corte. As características morfogênicas foram estudadas por meio da taxa de aparecimento de folhas (TApF), taxa de alongamento de folhas (TAlF) e colmos (TAlC), número de folhas emergentes (NFEm), expandidas (NFEx) e vivas (NFV). O perfilhamento foi maior para maior nível de irrigação. O clima proporcionou maior efeito nas características morfogênicas que os tratamentos. Os fatores estudados não proporcionaram efeito expressivo na TAlC, NFEm, NFEx e NFV.
\end{abstract}

Termos para indexação: Turno de rega, lâminas de irrigação, folha, alongamento.

\begin{abstract}
The aim of this work was to study the effect of different irrigation interval and irrigation depth on morphogenetic characteristics and tillering of the Panicum maximum Jacq. cv. Tanzania. The grass was cultivated in recipients in a greenhouse. The irrigations were performed with intervals of 1, 4 and 7 days, in order to reestablish soil water content to 50,75 and $100 \%$ of the total available water in the soil. The tillering was obtained through counting of living tiller after each cut. The morphogenetic characteristics were studied through the leaf appearance rate (LAR), leaf elongation rate (LER) and stem elongation rate (SER), emerging leaf numbers (EmLN), expanded leaf numbers (ExLN) and living leaf numbers (LLN). The tillering was larger for larger irrigation depth. The climate provided greater effect in the morphogenetic characteristics than the treatments. The studied factors were not significant for SER, EmLN, ExLN and LLN.
\end{abstract}

Index terms: Irrigation interval, irrigation depth, leaf, elongation.

\section{(Recebido em 29 de março de 2006 e aprovado em 25 de julho de 2006)}

\section{INTRODUÇÃO}

As pastagens, devido seu baixo custo de produção em relação aos concentrados, representam a forma mais prática e econômica de alimentação de bovinos e constituem a base de sustentação da pecuária do Brasil.

Alguns fatores como irregularidades do regime pluvial tornam-se uma restrição ao desenvolvimento de plantas forrageiras, pois mesmo dentro de estações chuvosas, observa-se períodos de déficit hídrico. A evapotranspiração da pastagem geralmente excede a precipitação pluvial, sendo assim, a distribuição de água em pastagens por meio de irrigação pode assegurar melhores índices de produtividade e de rentabilidade.

O sucesso na utilização de pastagens depende não só da disponibilidade de água, mas de um conjunto de fatores, como a compreensão dos mecanismos morfofisiológicos e de sua interação com o ambiente, ponto fundamental para suportar tanto o crescimento quanto a manutenção da capacidade produtiva da pastagem. Os estudos de fluxo de tecidos por meio de processos morfogênicos vêm se constituindo em importante ferramenta para avaliação da dinâmica de folhas e perfilhos em plantas forrageiras (GARCEZ NETO et al., 2002).

A morfogênese vegetal é definida como sendo a dinâmica de geração e expansão da forma da planta no espaço (LEMAIRE \& CHAPMAN, 1996), e segundo Fagundes et al. (2005), é geneticamente programada, porém influenciada por fatores ambientais como temperatura, disponibilidade hídrica, nutrientes, dentre outros.

\footnotetext{
'Engenheiro Agrônomo, Doutorando em Engenharia Agrícola - Departamento de Engenharia Agrícola - Universidade Federal de Viçosa/UFV - Ph Rolfs, s/n - 36571-000 - Viçosa, MG - fcunha@vicosa.ufv.br 2Engenheiro Agrícola, Professor Titular - Departamento de Engenharia Agrícola - Universidade Federal de Viçosa/UFV - Ph Rolfs, s/n - 36571-000 Viçosa, MG - aasoares@ufv.br

${ }^{3}$ Engenheiro Agrônomo, Professor Adjunto - Departamento de Zootecnia - Universidade Federal de Viçosa/UFV - Ph Rolfs, s/n - 36571-000 Viçosa, MG - odilon@ufv.br

${ }^{4}$ Graduando em Zootecnia, Departamento de Zootecnia - Universidade Federal de Viçosa/UFV - Ph Rolfs, s/n - 36571-000 - Viçosa, MG dmlambertucci@yahoo.com.br ; franklin.vitor1@bol.com.br
} 
A morfogênese de uma forrageira durante seu crescimento vegetativo é caracterizada por três fatores: a taxa de aparecimento de folhas, a taxa de alongamento de folhas e a longevidade das folhas (CHAPMAN \& LEMAIRE, 1993).

O aparecimento de folhas exerce um papel central na morfogênese, devido à sua influência direta sobre o tamanho da folha, densidade populacional de perfilhos e número de folhas vivas por perfilho (LEMAIRE \& CHAPMAN, 1996). A relação direta da taxa de aparecimento foliar com a densidade de perfilhos determina o potencial de perfilhamento para um dado genótipo, pois cada folha formada sobre uma haste representa o surgimento de um novo fitômero, ou seja, a geração de novas gemas axilares (NABINGER \& PONTES, 2001).

A taxa de alongamento das folhas parece ser a variável morfogênica que, isoladamente, mais se correlaciona diretamente com a massa seca da forragem (HORST et al., 1978). O alongamento foliar está restrito a uma zona na base da folha em expansão que está protegida pelo conjunto de bainhas das folhas mais velhas ou pseudocolmo, e é função do comprimento dessa zona de alongamento e da taxa de alongamento por segmento foliar (SKINNER \& NELSON, 1995).

A duração de vida da folha é o intervalo de tempo na qual uma dada folha permanece verde, ou seja, do seu aparecimento até a senescência (SBRISSIA, 2004). Segundo Alexandrino et al. (2005), a duração de vida da folha determina o número máximo de folhas vivas por perfilho, indicando a máxima quantidade de material vivo por área e a duração da fase de corte e início da senescência foliar.

Objetivou-se com este trabalho avaliar os efeitos de diferentes turnos de rega e níveis de irrigação sobre as características morfogênicas e o perfilhamento do Panicum maximum Jacq. cv. Tanzânia, cultivado em ambiente protegido.

\section{MATERIAL E MÉTODOS}

O experimento foi conduzido na Universidade Federal de Viçosa (UFV), localizada a $20^{\circ} 45^{\prime} \mathrm{S}$ e $42^{\circ} 45^{\prime} \mathrm{W}$, no Estado de Minas Gerais.

Uma bancada experimental foi instalada sob condições de ambiente protegido, para que as chuvas não influenciassem nos resultados do trabalho. Nessa estrutura foram colocados recipientes com 0,6 m de diâmetro e 1,0 m de altura com as plantas a serem avaliadas. Além disso, dentro dessa estrutura foi instalada uma estação meteorológica automática, com sensores de temperatura e radiação solar. Os dados foram armazenados a cada 12 minutos e registrados em médias horárias e, posteriormente, convertidos em médias diárias.

O solo utilizado no experimento foi o Latossolo Vermelho-Amarelo distrófico, cujos valores de capacidade de campo, ponto de murchamento e densidade foram de $38 \%, 23 \%$ e $1,05 \mathrm{~g} \mathrm{~cm}^{-3}$, respectivamente.

Os turnos de rega propostos para o trabalho foram de 1, 4 e 7 dias. Os níveis de irrigação que definiram o teor de água máximo no solo foram de 50, 75 e 100\% da disponibilidade total de água no solo, sendo fixado um nível de água no solo a ser atingido após cada irrigação, definido conforme equação 1, adaptada de Keller \& Bliesner (1990).

$$
U_{S A I}=\left[\frac{(C C-P M) T}{100}\right]+P M
$$

em que:

$\mathrm{U}_{\mathrm{SAI}}=$ Umidade do solo após a irrigação (\% em peso);

$\mathrm{CC}=$ Capacidade de campo do solo (\% em peso);

$\mathrm{PM}=$ Ponto de murchamento (\% em peso); e

$\mathrm{T}=$ Tratamento, fator nível de irrigação (\%).

A semeadura do capim foi realizada em 26/01/2004, utilizando-se sementes com valor cultural de $28 \%$. Após as plântulas atingirem uma altura de $5 \mathrm{~cm}$, efetivou-se um desbaste, deixando-se um estande de 20 plantas por recipiente. Aos 46 dias após a semeadura procedeu-se o corte de uniformização. A partir de então, foram realizados quatro cortes a $9 \mathrm{~cm}$ do nível do solo com idades de 31, 37, 61 e 52 dias. As plantas foram cortadas ao atingirem cerca de 1,0 $\mathrm{m}$ de altura.

A adubação foi constituída de doses de 50 e $40 \mathrm{mg} \mathrm{dm}^{-3} /$ corte de $\mathrm{N}$ e K, respectivamente, no corte 1 , e de 100 e $80 \mathrm{mg} \mathrm{dm}^{-3}$ / corte nos cortes 2,3 e 4 .

Para avaliar o número de perfilhos, procedeu-se a contagem dos perfilhos vivos após cada corte. Considerouse perfilhos mortos, os que apresentaram cor amarronzada.

Para as análises morfogências, foram avaliados a taxa de aparecimento de folhas (TApF), taxa de alongamento de folhas (TAlF) e colmo (TAlC), número de folhas emergentes (NFEm), expandidas (NFEx) e vivas (NFV). Dois perfilhos de cada unidade experimental foram selecionados e marcados com anéis coloridos de fio telefônico após cada corte. Com auxílio de uma régua, foram efetuadas medições do comprimento das lâminas foliares e do colmo dos perfilhos marcados, duas vezes por semana para o corte 3 , e três vezes por semana para os demais cortes, anotando-se os valores em planilhas previamente preparadas. 
O comprimento da lâmina emergente foi medido do seu ápice até a lígula da última folha expandida, a lâmina expandida teve seu comprimento medido da lígula até seu ápice e o comprimento do colmo foi medido do nível do solo até a lígula da última folha expandida (GOMIDE \& GOMIDE, 2000).

A partir dos dados obtidos das planilhas referentes ao estudo de crescimento de folhas, foram calculadas as seguintes variáveis: TApF subtraindo o número de folhas surgidas por perfilho, pelo número de dias envolvidos; TAlF subtraindo os comprimentos iniciais das lâminas de seus comprimentos finais, dividindo-se a diferença obtida pelo número de dias decorridos na avaliação e multiplicados pelo número de perfilhos considerados; TAlC subtraindo os comprimentos iniciais dos colmos de seus comprimentos finais, divididos pela diferença obtida pelo número de dias decorridos na avaliação e multiplicados pelo número de perfilhos considerados; NFEm obtido no final do período de crescimento, considerando como folhas emergentes ou em expansão aquelas que não apresentavam lígula exposta; NFEx obtido no final do período de crescimento, considerando o número de folhas expandidas de cada perfilho, ou seja, com lígula exposta; e NFV obtido no final do período de crescimento, somando o número de folhas em expansão e expandidas do perfilho (GOMIDE \& GOMIDE, 2000; OLIVEIRA, 2002; REZENDE et al., 2004).

$\mathrm{O}$ experimento foi instalado em esquema de parcelas subdivididas, tendo nas parcelas o esquema fatorial $3 \times 3$ (3 níveis de irrigação e 3 turnos de rega) e nas subparcelas os quatro cortes no delineamento inteiramente casualizado, com quatro repetições. Na comparação das médias adotouse o teste de Tukey ao nível de $5 \%$ de probabilidade. As análises estatísticas foram realizadas, empregando-se o software SAEG 8.0 desenvolvido pela UFV.

\section{RESULTADOS E DISCUSSÃO}

As variações de radiação solar e temperatura são mostradas na Figura 1. Os valores de radiação solar apresentaram grandes oscilações durante todo o período experimental e variaram de 42 a $242 \mathrm{~W} \mathrm{~m}^{-2}$. Os valores médios de temperatura durante o experimento variaram de 13,3 a $24,8{ }^{\circ} \mathrm{C}$, sendo máximos entre os meses de março a maio e de agosto e setembro, e mínimo entre os meses de junho e julho. Os valores médios de temperatura nos cortes 1, 2, 3 e 4 foram 23,$1 ; 21,2 ; 17,7$ e $18,9^{\circ} \mathrm{C}$, respectivamente.

Para densidade populacional de perfilhos do capimtanzânia, não foi observada interação entre os fatores nível de irrigação, turno de rega e corte, porém observou-se efeito $(p<0,05)$ isolado dos níveis de irrigação. Na Tabela 1 , observa-se maior $(p<0,05)$ densidade de perfilhos para o nível de irrigação de $100 \%$. Este resultado pode ser decorrente da maior disponibilidade de nitrogênio à planta quando o solo se apresenta com maior teor de água, pois segundo Premazzi et al. (2003), solos que apresentam elevado nível de nitrogênio estimulam o aparecimento de novos perfilhos. Outro fator, segundo Carvalho et al. (2001), que poderia influenciar o perfilhamento, seria a intensidade de pastejo, que neste experimento não existiu.

Gomide \& Gomide (2000), trabalhando com cultivares de Panicum maximum Jacq. sem irrigação, obtiveram média de 15 perfilhos por planta. Esse valor é maior do que os encontrados nesse trabalho, pois em cada recipiente havia 20 plantas, significando dessa forma para o nível de irrigação de $100 \%$, aproximadamente 7 perfilhos por planta. a

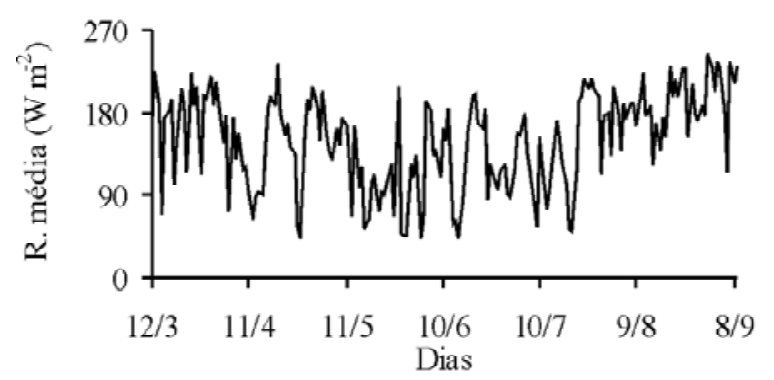

b

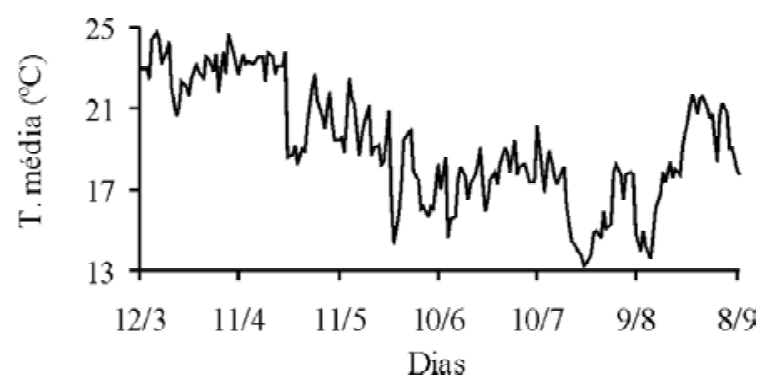

FIGURA 1 - Médias diária de radiação solar, em $\mathrm{W} \mathrm{m}^{-2}$ (a) e temperatura, em ${ }^{\circ} \mathrm{C}$ (b) dentro do ambiente protegido cultivado com capim-tanzânia durante o experimento.

Ciênc. agrotec., Lavras, v. 31, n. 3, p. 628-635, maio/jun., 2007 
TABELA 1 - Valores médios de densidade de perfilhos do capim-tanzânia para os três níveis de irrigação avaliados.

\begin{tabular}{lccc}
\hline Nível de irrigação $(\boldsymbol{\%})$ & $\mathbf{5 0}$ & $\mathbf{7 5}$ & $\mathbf{1 0 0}$ \\
\hline Perfilhos recipiente $^{-1}$ & $126,3 \pm 5,9 \mathrm{~b}$ & $130,0 \pm 4,5 \mathrm{~b}$ & $141,7 \pm 6,4 \mathrm{a}$ \\
\hline
\end{tabular}

Médias seguidas por diferentes letras diferem entre si pelo teste Tukey $(p<0,05)$.

Não foi observado efeito $(p>0,05)$ dos níveis de irrigação sobre a taxa de aparecimento de folhas (TApF) do capim-tanzânia, semelhante aos resultados obtidos por Andrade et al. (2005) para capim-elefante irrigado. Entretanto, houve interação $(p<0,05)$ entre os fatores turno de rega e cortes. Na Tabela 2 , observa-se que para os cortes 2,3 e 4, os turnos de rega não afetaram $(p>0,05)$ a TApF do capim-tanzânia, porém para o corte 1 que correspondeu ao período mais quente, registrou-se maior $(p<0,05)$ TApF para o turno de rega de 1 dia, seguido dos turnos de rega de 7 e 4 dias. Independentemente do turno de rega, observou-se menor $(p<0,05)$ TApF para o corte 3 , o qual apresentou temperaturas mais baixas. Paciullo et al. (2003), trabalhando com capim-elefante, também encontraram menores valores de TApF no período mais frio.

A TApF variou de 0,07 a 0,12 folha perfilho ${ }^{-1}$ dia $^{-1}$. Essa amplitude média foi inferior àquela encontrada por Barbosa et al. (2002) de 0,14 e 0,18 folha perfilho ${ }^{-1}$ dia $^{-1}$ para resíduo alto e baixo, respectivamente, e próximo aos observados por Gomide \& Gomide (2000) de 0,09 e 0,18 folhas perfilho ${ }^{-1} \mathrm{dia}^{-1}$ na rebrota e no estabelecimento da cultura, respectivamente, para a mesma cultivar avaliada no presente trabalho.

Para a taxa de alongamento de folhas (TAlF), observou-se interação $(p<0,01)$ entre os fatores nível de irrigação, turno de rega e cortes. Na Tabela 3, observa-se que independentemente do nível de irrigação, a TAlF não foi afetada $(p>0,05)$ pelo turno de rega. Para o turno de rega de 7 dias, registrou-se menor $(p<0,05)$ TAlF para o nível de irrigação de $50 \%$. Apesar de não ocorrer diferença significativa para os outros turnos de rega, os valores médios registrados indicaram que o nível de irrigação de $50 \%$ proporcionou menores TAlF. Andrade et al. (2005) observaram redução de $45 \%$ na TAlF do capim-elefante não-irrigado em relação ao irrigado. Segundo Ludlow \& $\mathrm{Ng}$ (1977), a expansão foliar é um dos processos fisiológicos mais sensíveis ao déficit hídrico, pois cessa o alongamento de folhas e raízes muito antes que os processos de fotossíntese e divisão celular sejam afetados.

Gomide \& Gomide (2000) encontraram valor médio de TAlF para o capim-tanzânia de $6,9 \mathrm{~cm}$ perfilho $\mathrm{o}^{-1} \mathrm{dia}^{-1}$. Santos et al. (2003), trabalhando com o mesmo capim, obtiveram valores entre 2,0 e 7,0 $\mathrm{cm}$ perfilho ${ }^{-1} \mathrm{dia}^{-1}$ para os meses de julho e fevereiro, respectivamente.
Não foi observado nenhum efeito e/ou interação $(p>0,05)$ dos níveis de irrigação e turnos de rega estudados sobre a taxa de alongamento de colmo (TAlC) do capimtanzânia, registrando-se valor médio de $0,443 \pm 0,172 \mathrm{~cm}$ perfilho ${ }^{-1} \mathrm{dia}^{-1}$.

Santos et al. (2003), trabalhando com capim-tanzânia e Fagundes et al. (2005) com o capim-braquiaria, encontraram TAlC médios de 0,08 e $0,14 \mathrm{~cm}_{\text {perfilho- }} \mathrm{dia}^{-1}$ para o inverno, e de 2,16 e $1,07 \mathrm{~cm}_{\text {perfilho }}^{-1} \mathrm{dia}^{-1}$ para o verão, respectivamente. A TAlC é importante por ser responsável por grande parte do crescimento da planta (SBRISSIA \& SILVA, 2001).

Houve interação $(p<0,01)$ entre os fatores nível de irrigação, turno de rega e cortes para número de folhas emergentes (NFEm). Na Tabela 4, observa-se que independentemente do nível de irrigação, o NFEm não foi afetado $(p>0,05)$ pelo turno de rega. Para o turno de rega de 1 dia, registrou-se menor $(p<0,05)$ NFEm para o nível de irrigação de $75 \%$.

Não foi observado efeito $(p>0,05)$ dos turnos de rega no número de folhas expandidas (NFEx), entretanto, houve interação $(p<0,05)$ entre níveis de irrigação e cortes. $\mathrm{O}$ clima proporcionou maior efeito no NFEx do que os tratamentos. Na Tabela 5, observa-se que para os níveis de irrigação de 75 e $100 \%$, constatam-se menores $(p<0,05)$ NFEx no corte 1 , no entanto, para o nível de irrigação de $50 \%$, os cortes 1 e 2 apresentaram menores médias. Analisando-se o efeito do nível de irrigação dentro de cortes, observa-se que o NFEx para os cortes 3 e 4 não variou $(p>0,05)$, porém para os cortes 1 e 2 , observa-se que o nível de irrigação de $50 \%$ apresentou menor $(p<0,05)$ NFEx em relação aos outros níveis de irrigação, ou seja, quanto maior foi a disponibilidade de água, maior foi o NFEx. Andrade et al. (2005) observaram redução de $13 \%$ no NFEx do capim-elefante não-irrigado em relação ao irrigado.

O número de folhas vivas (NFV) do capim-tanzânia não foi afetado $(p>0,05)$ pelos níveis de irrigação estudados, entretanto foi observado efeito $(p<0,01)$ da interação corte e turno de rega. Na Tabela 6, observa-se que para os turnos de rega de 4 e 7 dias, constata-se maiores $(p<0,05)$ NFV nos cortes 3 e 4, e para o turno de rega diário, observou-se maior $(p<0,05)$ NFV no corte 3 . Para os cortes 1 e 3 , registrou-se maiores médias de NFV no turno de rega de 1 dia. 
TABELA 2 - Taxa de aparecimento de folhas (TApF) em folhas perfilho ${ }^{-1}$ dia $^{-1}$ do capim-tanzânia para diferentes cortes e turno de rega, durante o período experimental.

\begin{tabular}{cclc}
\hline \multirow{2}{*}{ Corte } & \multicolumn{3}{c}{ Turno de rega (dias) } \\
\cline { 2 - 4 } & \multicolumn{1}{c}{$\mathbf{4}$} & $\mathbf{7}$ \\
\hline 1 & $0,121 \pm 0,011 \mathrm{Aa}$ & $0,088 \pm 0,014 \mathrm{BCc}$ & $0,104 \pm 0,008 \mathrm{Ab}$ \\
2 & $0,107 \pm 0,010 \mathrm{Ba}$ & $0,107 \pm 0,010 \mathrm{Aa}$ & $0,094 \pm 0,014 \mathrm{Aa}$ \\
4 & $0,086 \pm 0,006 \mathrm{Ca}$ & $0,080 \pm 0,008 \mathrm{Ca}$ & $0,074 \pm 0,006 \mathrm{Ba}$ \\
\hline
\end{tabular}

Para o corte, médias seguidas por mesma letra maiúscula e, para o turno de rega, médias seguidas por mesma letra minúscula, não diferem entre si pelo teste Tukey $(p>0,05)$.

TABELA 3 - Taxa de alongamento de folhas (TAlF) em $\mathrm{cm}_{\text {perfilho }}{ }^{-1}$ dia $^{-1}$ do capim-tanzânia para diferentes turnos de rega e níveis de irrigação no período experimental.

\begin{tabular}{cccc}
\hline \multirow{2}{*}{ Turno de rega (dias) } & \multicolumn{3}{c}{ Nível de irrigação (\%) } \\
\cline { 2 - 4 } & $\mathbf{5 0}$ & $\mathbf{7 5}$ & $\mathbf{1 0 0}$ \\
\hline 1 & $4,16 \pm 0,77 \mathrm{Aa}$ & $4,38 \pm 0,96 \mathrm{Aa}$ & $5,36 \pm 0,74 \mathrm{Aa}$ \\
4 & $3,44 \pm 0,55 \mathrm{Aa}$ & $3,72 \pm 0,31 \mathrm{Aa}$ & $4,78 \pm 0,97 \mathrm{Aa}$ \\
7 & $2,99 \pm 0,55 \mathrm{Ab}$ & $4,70 \pm 0,89 \mathrm{Aa}$ & $4,78 \pm 0,67 \mathrm{Aa}$ \\
\hline
\end{tabular}

Para o turno de rega, médias seguidas por mesma letra maiúscula, e para o nível de irrigação, médias seguidas por mesma letra minúscula, não diferem entre si pelo teste Tukey $(p<0,05)$.

TABELA 4 - Número de folhas emergentes (NFEm) em capim-tanzânia para diferentes turnos de rega e níveis de irrigação, durante o período experimental.

\begin{tabular}{cccc}
\hline \multirow{2}{*}{ Turno de rega (dias) } & \multicolumn{3}{c}{ Nível de irrigação (\%) } \\
\cline { 2 - 4 } & $\mathbf{5 0}$ & $\mathbf{7 5}$ & $\mathbf{1 0 0}$ \\
\hline 1 & $1,72 \pm 0,06 \mathrm{Aa}$ & $1,31 \pm 0,15 \mathrm{Ab}$ & $1,69 \pm 0,23 \mathrm{Aa}$ \\
7 & $1,78 \pm 0,16 \mathrm{Aa}$ & $1,59 \pm 0,16 \mathrm{Aa}$ & $1,47 \pm 0,29 \mathrm{Aa}$ \\
\hline & $1,53 \pm 0,12 \mathrm{Aa}$ & $1,63 \pm 0,22 \mathrm{Aa}$ & $1,53 \pm 0,16 \mathrm{Aa}$ \\
\hline
\end{tabular}

Para o turno de rega, médias seguidas por mesma letra maiúscula, e para o nível de irrigação, médias seguidas por mesma letra minúscula, não diferem entre si pelo teste Tukey $(p<0,05)$.

TABELA 5 - Número de folhas expandidas (NFEx) em capim-tanzânia para diferentes cortes e níveis de irrigação, durante o período experimental.

\begin{tabular}{cccc}
\hline \multirow{2}{*}{ Corte } & \multicolumn{3}{c}{ Nível de irrigação (\%) } \\
\cline { 2 - 4 } & $\mathbf{5 0}$ & $\mathbf{7 5}$ & $\mathbf{1 0 0}$ \\
\hline 1 & $2,54 \pm 0,14 \mathrm{Bb}$ & $2,83 \pm 0,19 \mathrm{Ca}$ & $2,88 \pm 0,25 \mathrm{Ca}$ \\
2 & $2,33 \pm 0,14 \mathrm{Bb}$ & $3,17 \pm 0,20 \mathrm{Ba}$ & $3,42 \pm 0,26 \mathrm{ABa}$ \\
3 & $3,46 \pm 0,33 \mathrm{Aa}$ & $3,58 \pm 0,26 \mathrm{Aa}$ & $3,62 \pm 0,27 \mathrm{Aa}$ \\
4 & $3,17 \pm 0,15 \mathrm{Aa}$ & $3,21 \pm 0,14 \mathrm{Ba}$ & $3,29 \pm 0,08 \mathrm{Ba}$ \\
\hline
\end{tabular}

Para o corte, médias seguidas por mesma letra maiúscula e, para o nível de irrigação, médias seguidas por mesma letra minúscula, não diferem entre si pelo teste Tukey $(p>0,05)$. 
TABELA 6 - Número de folhas vivas (NFV) em capim-tanzânia para diferentes cortes e turno de rega, durante o período experimental.

\begin{tabular}{cccc}
\hline \multirow{2}{*}{ Corte } & \multicolumn{3}{c}{ Turno de rega (dias) } \\
\cline { 2 - 4 } & $\mathbf{1}$ & $\mathbf{4}$ & $\mathbf{7}$ \\
\hline 1 & $4,62 \pm 0,33 \mathrm{Ba}$ & $3,92 \pm 0,15 \mathrm{Cc}$ & $4,17 \pm 0,15 \mathrm{Bb}$ \\
2 & $4,58 \pm 0,25 \mathrm{Bab}$ & $4,71 \pm 0,21 \mathrm{Ba}$ & $4,38 \pm 0,19 \mathrm{Bb}$ \\
4 & $5,29 \pm 0,17 \mathrm{Aa}$ & $5,04 \pm 0,16 \mathrm{Ab}$ & $5,04 \pm 0,09 \mathrm{Ab}$ \\
4 & $4,67 \pm 0,21 \mathrm{Bb}$ & $5,04 \pm 0,17 \mathrm{Aa}$ & $5,04 \pm 0,13 \mathrm{Aa}$ \\
\hline
\end{tabular}

Para o corte, médias seguidas por mesma letra maiúscula e, para o turno de rega, médias seguidas por mesma letra minúscula, não diferem entre si pelo teste Tukey $(p>0,05)$.

O NFV variou de 3,9 a 5,3 e foi semelhante ao valor encontrado por Gomide \& Gomide (2000) para a mesma forrageira estudada, que foi de 5 folhas vivas por perfilho. Segundo Oliveira (2002), devido à constância da característica NFV, mesmo quando a forrageira é submetida a diferentes adubações, condições de clima e manejo, este índice poderia ser utilizado para definir o intervalo de cortes. Segundo Gomide \& Gomide (2000), durante o desenvolvimento da forrageira, o NFV cresce enquanto não se instala o processo de senescência e morte de folhas.

Analisando os resultados apresentados para NFV, NFEm e NFEx, pode-se inferir em geral que a irrigação não seja suficiente para causar variações expressivas em tais valores, sendo a temperatura nos diferentes períodos, elemento mais eficiente.

\section{CONCLUSÕES}

O perfilhamento foi maior para o maior nível de irrigação.

Em geral, o clima proporcionou maior efeito nas características morfogênicas que os tratamentos. A TApF não foi afetada pelo nível de irrigação e o turno de rega diário proporcionou maiores $\mathrm{TApF}$ no período mais quente. A TAlF foi menor no tratamento de menor nível de irrigação. A TAlC não foi afetada por níveis de irrigação e turnos de rega. Os fatores estudados não proporcionaram em geral efeito expressivo no NFEm, NFEx e NFV.

\section{REFERÊNCIAS BIBLIOGRÁFICAS}

ALEXANDRINO, E.; NASCIMENTO JÚNIOR, D.; REGAZZI, A. J.; MOSQUIM, P. R.; ROCHA, F. C.; SOUZA, D. P. Características morfogênicas e estruturais da Brachiaria brizantha $\mathrm{cv}$. Marandu submetida a diferentes doses de nitrogênio e freqüências de cortes. Acta Scientiarum Agronomy, Maringá, v. 27, n. 1, p. 17-24, 2005.
ANDRADE, A. C.; FONSECA, D. M.; LOPES, R. S.; NASCIMENTO JÚNIOR, D.; CECON, P. R.; QUEIROZ, D. S.; PEREIRA, D. H.; REIS, S. T. Características morfogênicas do capim-elefante "Napier" adubado e irrigado. Ciência e Agrotecnologia, Lavras, v. 29, n. 1, p. 150-159, 2005.

BARBOSA, R. A.; NASCIMENTO JÚNIOR, D.; EUCLIDES, V. P. B.; REGAZZI, A. J.; FONSECA, D. M. Características morfogênicas e acúmulo de forragem do capim-tanzânia (Panicum maximum Jacq. cv. Tanzânia) em dois resíduos forrageiros pós-pastejo. Revista Brasileira de Zootecnia, Viçosa, v. 31, n. 2, p. 583-593, 2002.

CARVALHO, C. A. B.; SILVA, S. C.; SBRISSIA, A. F.; PINTO, L. F. M.; CARNEVALLI, R. A.; FAGUNDES, J. L.; PEDREIRA, C. G. S. Demografia do perfilhamento e acúmulo de matéria seca em coastcross submetido a pastejo. Pesquisa Agropecuária Brasileira, Brasília, v. 36, n. 3, p. 567-575, 2001.

CHAPMAN, D. F.; LEMAIRE, G. Morphogenetic and structural determinants of plant regrowth after defoliation. In: INTERNATIONAL GRASSLAND CONGRESS, 17. 1993, Austrália. Proceedings... Australia: [s.n.], 1993. p. 95-104.

FAGUNDES, J. L.; FONSECA, D. M.; GOMIDE, J. A.; NASCIMENTO JÚNIOR, D.; VITOR, C. M. T.; MORAIS, R. V.; MISTURA, C.; REIS, G. C.; MASTUSCELLO, J. A. Acúmulo de forragem em pastos de Brachiaria decumbens adubados com nitrogênio. Pesquisa Agropecuária Brasileira, Brasília, v. 40, n. 4, p. 397-403, 2005. 
GARCEZ NETO, A. F.; NASCIMENTO JÚNIOR, D.; REGAZZI, A. J.; FONSECA, D. M.; MOSQUIM, P. R.; GOBBI, K. F. Respostas morfogênicas e estruturais de Panicum maximum cv. Mombaça sob diferentes níveis de adubação nitrogenada e alturas de corte. Revista Brasileira de Zootecnia, Viçosa, v. 31, n. 5, p. 1890-1900, 2002.

GOMIDE, C. A. M.; GOMIDE, J. A. Morfogênese de cultivares de Panicum maximum Jacq. Revista Brasileira de Zootecnia, Viçosa, v. 29, n. 2, p. 341-348, 2000.

HORST, G. L.; NELSON, C. J.; ASAY, K. H. Relationship of leaf elongation to forage yield of tall fescue genotypes. Crop Science, Madison, v. 18, n. 5, p. 715-719, 1978.

KELLER, J.; BLIESNER, R. D. Sprinkle and Trickle irrigation. New York: AVI Book, 1990. 652 p.

LEMAIRE, G.; CHAPMAN, D. F. Tissue flows in grazed plant communities. In: HODGSON, J.; ILLIUS, A. W. (Eds.). The ecology and management of grazing systems. Wallingford, UK: CAB International, 1996. p. 3-36.

LUDLOW, M. M.; NG, T. T. Leaf elongation rate in Panicum maximum var. trichoglume following removal of water stress. Australian Journal of Plant Physiology, Melbourne, v. 4, n. 2, p. 263-272, 1977.

NABINGER, C.; PONTES, L. S. Morfogênese de plantas forrageiras e estrutura do pasto. In: REUNIÃO DA SOCIEDADE BRASILEIRA DE ZOOTECNIA, 38., 2001, Piracicaba. Anais... Piracicaba: SBZ, 2001. p. 755-771.

OLIVEIRA, M. A. Características morfofisiológicas e valor nutritivo de gramíneas forrageiras do gênero Cynodon sob diferentes condições de irrigação, fotoperíodo, adubação nitrogenada e idades de rebrota. 2002. 142 f. Tese (Doutorado em Zootecnia) - Universidade Federal de Viçosa, Viçosa, 2002.
PACIULLO, D. S. C.; DERESZ, F.; AROEIRA, L. J. M.; MORENZ, M. J. F.; VERNEQUE, R. S. Morfogênese e acúmulo de biomassa foliar em pastagem de capim-elefante avaliada em diferentes épocas do ano. Pesquisa Agropecuária Brasileira, Brasília, v. 38, n. 7, p. 881-887, 2003.

PREMAZZI, L. M.; MONTEIRO, F. A.; CORRENTE, J. E. Perfilhamento em capim-bermuda cv. Tifton 85 em resposta a doses e ao momento de aplicação do nitrogênio após o corte. Scientia Agrícola, Piracicaba, v. 60, n. 3, p. 565-571, 2003.

REZENDE, C. P.; PINTO, J. C.; PEREIRA, J. M.; MUNIZ, J. A.; ANDRADE, I. F.; EVANGELISTA, A. R. Características morfológicas do capim-elefente e capimbraquiarão submetidos a diferentes taxas de lotação. Ciência e Agrotecnologia, Lavras, v. 28, n. 2, p. 414-421, 2004.

SANTOS, P. M.; BALSALOBRE, M. A. A.; CORSI, M. Morphogenetic characteristics and management of Tanzania grass. Pesquisa Agropecuária Brasileira, Brasília, v. 38, n. 8, p. 991-997, 2003.

SBRISSIA, A. F. Morfogênese, dinâmica do perfilhamento e do acúmulo de forragem em pastos de capim-marandu sob lotação contínua. 2004. 171 f. Tese (Doutorado em Agronomia) - Escola Superior de Agricultura "Luiz de Queiroz", Piracicaba, 2004.

SBRISSIA, A. F.; SILVA, S. C. O ecossistema de pastagens e a produção animal. In: REUNIÃO ANUAL DA SOCIEDADE BRASILEIRA DE ZOOTECNIA, 38., 2001, Piracicaba. Anais... Piracicaba: SBZ, 2001. p. 731-754.

SKINNER, R. H.; NELSON, C. J. Elongation of the grass leaf and its relationship to the phyllochron. Crop Science, Madison, v. 35, n. 1, p. 4-10, 1995. 


\section{ANEXO}

Análise de variância.

\begin{tabular}{|c|c|c|c|c|c|c|c|c|}
\hline \multirow{2}{*}{ FV } & \multirow{2}{*}{ GL } & \multicolumn{7}{|c|}{ QM } \\
\hline & & Perfilho & TApF & TAIF & TAIC & NFEm & NFEx & NFV \\
\hline NI & 2 & $4.480 *$ & $0,11 \mathrm{E}-2^{\mathrm{NS}}$ & $24,94 * *$ & $0,304^{\mathrm{NS}}$ & $0,349^{\mathrm{NS}}$ & $2,380 * *$ & $1,172^{\mathrm{NS}}$ \\
\hline TR & 2 & $308^{\mathrm{NS}}$ & $0,13 \mathrm{E}-2^{\mathrm{NS}}$ & $5,49^{\mathrm{NS}}$ & $0,063^{\mathrm{NS}}$ & $0,036^{\mathrm{NS}}$ & $0,328^{\mathrm{NS}}$ & $0,255^{\mathrm{NS}}$ \\
\hline NI $x$ TR & 4 & $611^{\mathrm{NS}}$ & $0,17 \mathrm{E}-3^{\mathrm{NS}}$ & $2,93^{\mathrm{NS}}$ & $0,069^{\mathrm{NS}}$ & $0,456 *$ & $0,099^{\mathrm{NS}}$ & $0,161^{\mathrm{NS}}$ \\
\hline Resíduo A & 27 & 1.007 & $0,77 \mathrm{E}-3$ & 3,71 & 0,115 & 0,182 & 0,414 & 0,648 \\
\hline Corte & 3 & $1,3 \mathrm{E}+5 * * *$ & $0,45 \mathrm{E}-2 * * *$ & $6,92 * *$ & $1,756 * * *$ & $0,264^{\mathrm{NS}}$ & $4,306 * * *$ & $5,560 * * *$ \\
\hline $\mathrm{NI} \times \mathrm{C}$ & 6 & $894 *$ & $0,53 \mathrm{E}-3^{\mathrm{NS}}$ & $2,57^{\mathrm{NS}}$ & $0,072^{\mathrm{NS}}$ & $0,307^{\mathrm{NS}}$ & $0,672 *$ & $0,496^{\mathrm{NS}}$ \\
\hline TR x C & 6 & $518^{\mathrm{NS}}$ & $0,11 \mathrm{E}-2 *$ & $0,84^{\mathrm{NS}}$ & $0,034^{\mathrm{NS}}$ & $0,189^{\mathrm{NS}}$ & $0,550^{\mathrm{NS}}$ & $0,815 * *$ \\
\hline NIxTRxC & 12 & $613^{\mathrm{NS}}$ & $0,80 \mathrm{E}-3^{\mathrm{NS}}$ & $3,68 * *$ & $0,079^{\mathrm{NS}}$ & $0,470 * *$ & $0,370^{\mathrm{NS}}$ & $0,348^{\mathrm{NS}}$ \\
\hline Resíduo B & 81 & 329 & $0,45 \mathrm{E}-3$ & 1,49 & 0,069 & 0,193 & 0,285 & 0,230 \\
\hline
\end{tabular}

$* p<0,05 ; \quad * * p<0,01 ; \quad * * * p<0,001 ; \quad{ }^{\text {NS }}$ não-significativo. 